\title{
PEMANFAATAN SMARTPHONE PADA ROBOT BERODA UNTUK MONITORING JARAK ROBOT DENGAN HALANGAN MENGGUNAKAN BLUETOOTH HC-05 SEBAGAI MEDIA KOMUNIKASI
}

\author{
Nanda Tommy Wirawan \\ E-mail : nandatommyw@upiyptk.ac.id
}

\begin{abstract}
Abstak
Penelitian ini bertujuan untuk mengembangkan robot yang bisa memonitoring hambatan yang ada pada wilayah robot, robot ini menggunakan sensor ultrasonik sebagai sensor untuk mendeteksi hambatan dan bluetooth HC-05 sebagai alat komunikasi antara robot dengan Smartphone. Manfaat dari aplikasi ini adalah memahami bagaimana robot bisa mendeteksi jarak halangan sehingga bisa memberikan data halangan ke Smartphone sehingga kita bisa mengetahui berapa jarak halangan tersebut.

Penelitian ini dilakukan dengan merancang, membuat dan mengimplementasikan komponen sistem yang meliputi mikroprosesor sebagai pengendali proses, sensor ultrasonik sebagai media deteksi halangan, dan motor DC sebagai motor gerak pada roda. Hasil penelitian menunjukkan bahwa alat yang dibuat berfungsi dengan baik dan dapat dikembangkan untuk skala yang lebih besar.
\end{abstract}

Kata kunci: Smartphone, Robot, Bluetooth, Sensor Ultrasonik.

\section{Pendahuluan}

Smartphone adalah sebuah alat komunikasi yang banyak digunakan oleh kalangan masyarakat dan terutama dikalangan pelajar maupun mahasiswa, yang mana smartphone hanya digunakan untuk media sosial dan alat komunikasi lain nya. Tapi disisi lain Smartphone juga bisa dimanfaatkan kedalam dunia robotika contohnya saja digunakan dalam alat komunikasi antara robot.

Dan dalam dunia pendidikan robot merupakan hal yang cukup lama telah diketahui, tetapi masih kurangnya pengetahuan mengenai robot sering membuat seseorang menjadi bingung bagaimana mengaplikasikan sebuah robot pada suatu kebutuhan.

Untuk masalah tersebut, penulis mencoba merancang suatu sistem agar dapat menjadi salah satu contoh yang mana Smartphone tidak hanya digunakan untuk media sosial dan komunikasi saja, tetapi Smartphone juga bisa digunakan sebagai alat komunikasi pada robot yaitu Sebagai Penggerak Robot dan memonitoring jarak robot dengan halangan. Tujuan utama dari penelitian ini adalah untuk merancang suatu sistem yang mampu memonitoring jarak robot dengan halangan yang berada di sisi depan, kiri dan kanan robot. Hal ini bertujuan agar sistem yang dirancang dapat dikembangkan diberbagai macam aplikasi yang dibutuhkan dan juga menambah pengetahuan mengenai robotik.

\section{Tinjauan Literatur}

\subsection{System Development Life Cycle (SDLC)}

Pengembangan sistem informasi yang berbasis komputer dapat merupakan tugas kompleks yang membutuhkan banyak sumber daya dan dapat memakan waktu berbulan-bulan bahkan bertahun-tahun untuk menyelesaikannya. Proses pengembangan sistem melewati beberapa tahapan 
dari mulai sistem itu direncanakan sampai dengan sistem tersebut diterapkan, dioperasikan dan dipelihara. Bila operasi sudah dikembangkan masih timbul kembali permasalahan-permasalahan yang kritis serta tidak dapat diatasi dalam tahap pemeliharaan sistem, maka perlu dikembangkan kembali suatu sistem untuk mengatasinya dan proses ini kembali ketahap pertama, yaitu tahap perencanaan sistem, siklus ini disebut dengan siklus hidup suatu sistem (System development life cycle). Daur atau siklus dari pengembangan sistem merupakan suatu bentuk yag digunakan untuk menggambarkan tahapan utama dan langkah-langkah didalam tahapan tersebut dalam pengembangannya.

Ide dari system life cycle adalah sederhana dan masuk akal. Di system development life cycle, tiap-tiap bagian dari pengembangan sistem dibagi menjadi tahapan kerja. Tiap-tiap tahapan ini mempunyai karakteristik tersendiri. Tahapan utama siklus hidup pengembangan sistem dapat terdiri dari tahapan perencanaan sistem (systems planning), analisa system (systems analysis), desain sistem (system design), seleksi sistem (systems selection), implementasi sistem (system implementation) dan perawatan sistem (system maintenance). Tahapan-tahapan seperti ini sebenarnya merupakan tahapan didalam pengembangan sistem teknik (engineering systems).

Istilah software engineering merupakan proses pengembangan perangkat lunak yang merupakan subsistem dari pengembangan sistem informasi.

Sebelum suatu sistem dikembangakan, umumnya terlebih dahulu dimulai dengan adanya adanya suatu kebijakan dan perencanaan unutk mengembangakan sistem itu. Tanpa adanya perencanaan yang baik, pengembangan sistem tidak dapat diharapkan seperti yang diharapkan. Tanpa adanya kebijakan pengembangan sistem oleh manajemen puncak, maka pengembangan sistem tidak akan mendapatkan dukungan dari manajemen puncak (top managemen), padahal dukungan tersebut sangat penting artinya. Kebijakan sistem merupakan landasan dan dukungan dari manajemen puncak untuk membuat perencanaan.

Secara umum siklus hidup pengembangan sistem dapat digambarkan berikut ini :

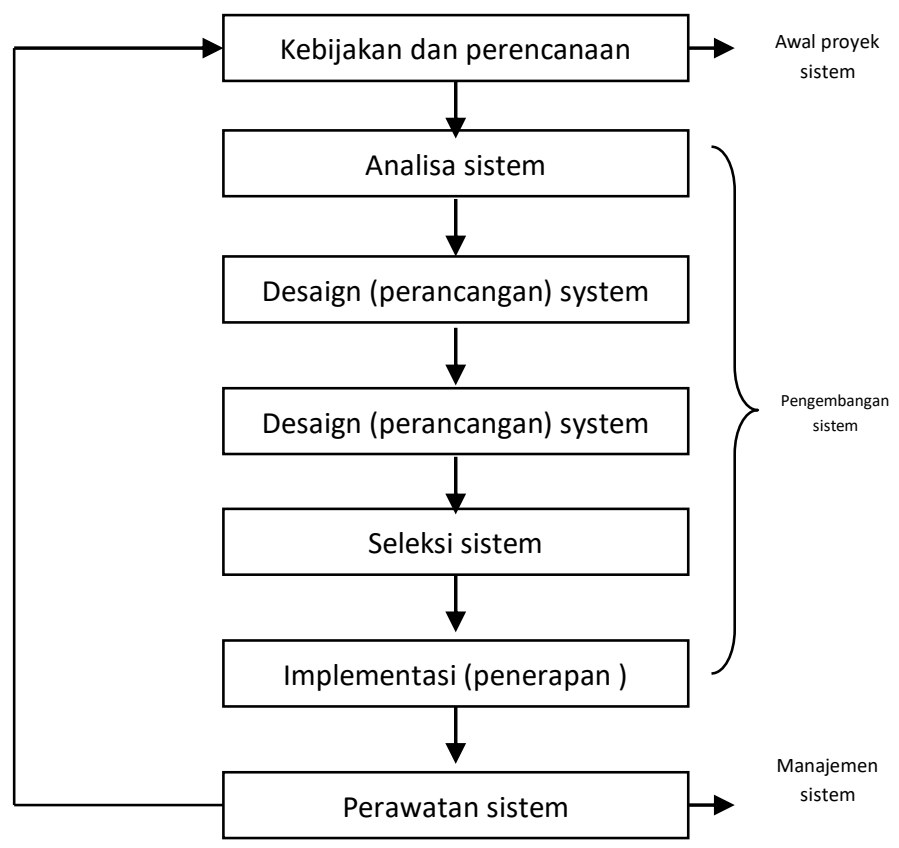

\subsection{Mikrokontroler ATMEGA8535}


Mikrokontroler, sebagai suatu terobosan teknologi mikroprosesor hadir memenuhi kebutuhan pasar (need market) dan teknologi baru. Sebagai teknologi baru, yaitu teknologi semikonduktor dengan kandungan transistor yang lebih banyak namun hanya membutuhkan ruang yang kecil serta diproduksi secara masal yang membuat harganya lebih murah ( dibandingkan mikroprosesor ). Sebagai kebutuhan pasar, Mikrokontroller hadir untuk memenuhi selera industri dan para konsumen akan kebutuhan dan keinginan peralatan yang lebih canggih.

Mikrokontroller ATmega8535 merupakan salah satu mikrokontroler keluaran ATMEL dengan 8 Kilobyte flash perom ( Programble and Erasable Read Only Memory), ATmega8535 memiliki memori dengan teknologi nonvolatile memori, isi memori tersebut dapat diisi ulang ataupun dihapus berkali-kali. Memori bisa digunakan sesuai dengan program dan fungsinya.

Mikrokontroler ATmega 8535 secara garis besar terdiri dari CPU yang terdiri dari 32 buah register, saluran I/O, ADC, Port antarmuka, Port serial. Mikrokontroler ATmega 8535 merupakan anggota keluarga mikrokontroler AVR (Alf and Vegard's Risc Processor).

\subsubsection{Arsitektur ATMEGA 8535}

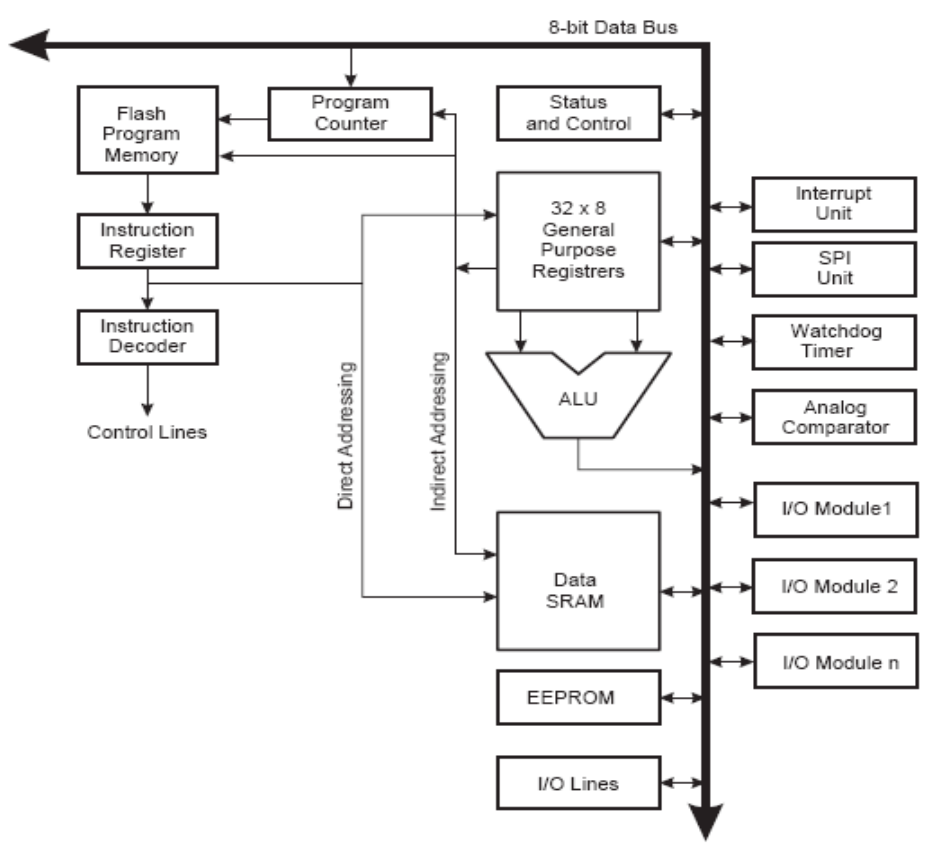

Gambar 2.2 Arsitektur ATmega8535

Mikrokontroler ATmega8535 memiliki arsitektur Harvard, yaitu memisahkan memori untuk kode program dan memori untuk data sehingga dapat memaksimalkan unjuk kerja dan paralelisme. Instruksi-instruksi dalam memori program dieksekusi dalam satu alur tunggal, dimana pada saat satu instruksi dikerjakan instruksi berikutnya sudah diambil (pre-fetched) dari memori program. Konsep inilah yang memungkinkan instruksi-instruksi dapat dieksekusi dalam setiap satu siklus clock. 
32 x 8-bit register serba guna digunakan untuk mendukung operasi pada Arithmetic Logical Unit (ALU) yang dapat dilakukan dalam satu siklus. 6 dari egister serbaguna ini dapat digunakan sebagai 3 buah register pointer 16 bit pada mode pengalamatan tak langsung untuk mengambil data pada ruang memori data. Ketiga register pointer 16 bit ini disebut dengan register X (gabungan R26 dan R27), register Y (gabungan R28 dan R29), dan register Z (gabungan R30 dan R31).

Hampir semua instruksi AVR memiliki format 16-bit (word). Setiap alamat memori program terdiri dari instruksi 16-bit atau 32-bit. Selain register serbaguna di atas, terdapat register lain yang terpetakan dengan teknik memory mapped I/O selebar 64 Byte. Beberapa register ini digunakan untuk fungsi khusus antara lain sebagai register control Timer/Counter, interupsi, ADC, USART, SPI, EEPROM dan fungsi I/O lainnya. Register - register ini menempati memori pada alamat $0 \mathrm{x} 20 \mathrm{~h}-0 \mathrm{x} 5 \mathrm{fh}$.

\subsubsection{Konfigurasi Pin dan Penjelasan}

Susunan pin-pin mikrokontroler ATmega 8535 diperlihatkan pada gambar 2.3. Penjelasan masing-masing pin sebagai berikut :

\begin{tabular}{|c|c|c|c|c|}
\hline (XCK/TO) PBO 口 & 1 & 40 & $\ominus \mathrm{PAO}$ & $(A D C 0)$ \\
\hline (T1) PB1 $\square$ & 2 & 39 & $\square$ PA1 & (ADC1) \\
\hline 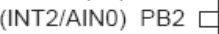 & 3 & 38 & $\square$ PA2 & $(\mathrm{ADC} 2)$ \\
\hline 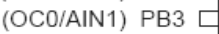 & 4 & 37 & $\square$ PA3 & (ADC3) \\
\hline$(\overline{\mathrm{SS}})$ PB4 & 5 & 36 & $\square$ PA4 & (ADC4) \\
\hline (MOSI) PB5 Б & 6 & 35 & $\square$ PA5 & (ADC5) \\
\hline (MISO) PB6 무 & 7 & 34 & $\square$ PA6 & (ADC6) \\
\hline (SCK) PB7 口 & 8 & 33 & $\square$ PA7 & (ADC7) \\
\hline$\overline{\text { RESET }}$ & 9 & 32 & $\sqsupset$ AREF & \\
\hline VCC & 10 & 31 & $\sqsupseteq$ GND & \\
\hline GND $\square$ & 11 & 30 & $\sqsupseteq$ AVCO & \\
\hline XTAL2 무 & 12 & 29 & $\sqsupseteq$ PC7 & (TOSC2) \\
\hline XTAL1 & 13 & 28 & $\square$ PC6 & (TOSC1) \\
\hline (RXD) PD0 口 & 14 & 27 & $\sqsupset$ PC5 & (TDI) \\
\hline (TXD) PD1 & 15 & 26 & $\sqsupseteq$ PC4 & (TDO) \\
\hline (INT0) PD2 & 16 & 25 & $\ominus \mathrm{PC} 3$ & (TMS) \\
\hline (INT1) PD3 口 & 17 & 24 & $\sqsupset$ PC2 & (TCK) \\
\hline (OC1B) PD4 만 & 18 & 23 & $\square \mathrm{PC} 1$ & (SDA) \\
\hline (OC1A) PD5 Б & 19 & 22 & $\sqsupseteq \mathrm{PCO}$ & (SCL) \\
\hline (ICP1) PD6 口 & 20 & 21 & PD7 & (OC2) \\
\hline
\end{tabular}

Gambar 2.3 Susunan pin (kaki) Mikrokontroler Atmega8535

1. Pin $1-8$ adalah Port $\mathrm{B}$ ( $\mathrm{PB} 0$ - $\mathrm{PB} 7$ ) merupakan pin $\mathrm{I} / \mathrm{O}$ dua arah dan pin fungsi khusus, yaitu timer/ counter, komparator analog, dan SPI.

2. Pin 9 (reset) adalah pin yang digunakan untuk mereset mikrokontroler, dan bekerja bila diberi pulsa rendah (aktif low) selama minimal 1.5 us.

3. Pin $10(\mathrm{Vcc})$ merupakan pin masukan positif catu daya. Setiap peralatan eletronika digital tentunya butuh sumber catu daya yang umumnya sebesar 5V itulah sebabnya di PCB kit mikrokontroler selalu ada IC regulator 7805 .

4. Pin 11 (Ground) sebagai pin ground.

5. Pin 12 dan Pin 13 (XTAL 2 dan XTAL 1) sebagai pin masukan clock exsternal. Suatu mikrokontroler membutuhkan sumber detak atau clock agar dapat mengeksekusi instruksi yang ada di memori. Semakin tinggi nilai kristalnya maka semakin cepat mikrokontroler tersebut. 
6. Pin $14-21$ adalah Port D (D0 - D7 ) merupakan pin I/O dua arah dan pin fungsi khusus yaitu komparator analog, interupsi internal dan komunikasi serial.

7. Pin $22-29$ adalah Port $\mathrm{C}$ (PC0 - PC7) merupakan pin $\mathrm{I} / \mathrm{O}$ dua arah dan pin fungsi khusus yaitu TWI, komparator analog, dan timer osilator.

8. Pin 30 (AVCC) sebagai pin masukan tegangan untuk ADC.

9. Pin 31 (GND) sebagai pin ground.

10. Pin 32 (AREF) sebagai pin masukan tegangan referensi analog untuk ADC.

11. Pin 33 - 40 adalah Port A (PA0 - PA7) merupakan pin I/O dua arah dan dapat diprogram sebagai pin masukan 8 chanel ADC.

\subsection{Sensor Ultrasonic}

Gelombang ultrasonik merupakan gelombang mekanik longitudinal (gelombang yang amplitudonya berubah-ubah) dengan frekuensi di atas $20 \mathrm{kHz}$. Gelombang ini dapat merambat dalam medium padat, cair dan gas, hal ini disebabkan karena gelombang ultrasonik merupakan rambatan energi dan momentum mekanik sehingga merambat sebagai interaksi dengan molekul dan sifat enersia medium yang dilaluinya

Karakteristik gelombang ultrasonik yang melalui medium mengakibatkan getaran partikel dengan medium amplitudo (tinggi maksimum gelombang) sejajar dengan arah rambat secara longitudinal sehingga menyebabkan partikel medium membentuk rapatan (Strain) dan regangan (Stress). Proses kontinu yang menyebabkan terjadinya rapatan dan regangan di dalam medium disebabkan oleh getaran partikel secara periodik selama gelombang ultrasonik melaluinya.

Sensor ultrasonik mempunyai prinsip kerja yang hampir sama dengan radar atau sonar yang mengevaluasi atribut target dengan menginprentasikan gema dari gelombang suara atau radio yang berturut-turut. Sensor ultrasonik menghasilkan gelombang suara frekwensi tinggi dan mengevaluasi gema yang diterima kembali oleh sensor. Sensor menghitung waktu interval antara pengiriman sinyal dan penerimaan gema untuk menentukan jarak dari suatu objek.

Berikut pada gambar 2.4 adalah cara kerja sensor ultrasonik.

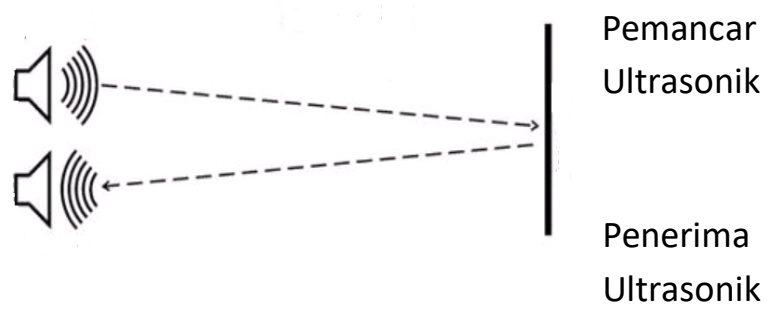

\section{Gambar 2.4 Prinsip Kerja Sensor Ultrasonik}

Sensor ultrasonik yang digunakan adalah produksi Parallax Inc bermerek PING. Sensor ini menyediakan perhitungan jarak mulai dari $3 \mathrm{~cm}$ hingga 3 meter.

\subsection{Bluetooth HC-05}


Bluetooth adalah protokol komunikasi wireless yang bekerja pada frekuensi radio $2.4 \mathrm{GHz}$ untuk pertukaran data pada perangkat bergerak seperti PDA, laptop, HP, dan lain - lain. Salah satu hasil contoh modul Bluetooth yang paling banyak digunakan adalah tipe HC-05. Modul Bluetooth HC-05 merupakan salah satu modul Bluetooth yang dapat ditemukan dipasaran dengan harga yang relatif murah. Modul Bluetooth HC-05 terdiri dari 6 pin konektor, yang setiap pin konektor memiliki fungsi yang berbeda -beda. Untuk gambar module bluetooth dapat dilihat pada gambar 2.2:

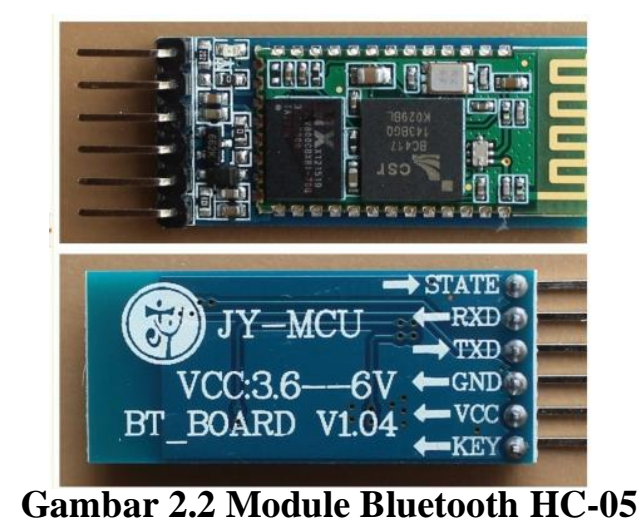

Modul Bluetooth HC-05 dengan supply tegangan sebesar 3,3 V ke pin 12 modul Bluetooth sebagai VCC. Pin 1 pada modul Bluetooth sebagai transmitter. Kemudian pin 2 pada Bluetooth sebagai receiver.

Berikut merupakan konfigurasi pin bluetoooth HC-05 ditunjukkan pada tabel 2.1 dibawah ini:

Tabel 2.1 Konfigurasi Pin Module Bluetooth HC-05

\begin{tabular}{|l|l|l|}
\hline Nomor Pin & \multicolumn{1}{|c|}{ Nama } & \multicolumn{1}{c|}{ Fungsi } \\
\hline Pin 1 & Key & - \\
\hline Pin 2 & VCC & Sumber Tegangan 5V \\
\hline Pin 3 & GND & Ground Tegangan \\
\hline Pin 4 & TXD & Mengirim Data \\
\hline Pin 5 & RXD & Menerima Data \\
\hline Pin 6 & STATE & - \\
\hline
\end{tabular}

\subsection{Motor DC}

Motor arus searah (DC) adalah suatu mesin yang berfungsi mengubah tegangan listrik DC menjadi tenaga mekanis dimana tenaga gerak merupakan putaran dari pada rotor. Dalam kehidupan sehari-hari motor DC dapat pada motor stater mobil, tape recorder, mainan anak-anak dan sebagainya. Pada prinsipnya motor arus searah dapat dipakai sebagai generator arus searah sebaliknya generator arus searah dapat dipakai sebagai motor arus searah.

Pada prinsipnya, setiap jenis motor listrik dapat digunakan dalam perancangan pengontrolan secara elektronik terhadap kecepatan dan daya yang disesuaikan dengan beban yang akan digerakkan oleh motor tersebut. Pada perancangan dan pembuatan alat ini digunakan motor DC yang berfungsi untuk menggerakkan persendian pada lengan robot. Untuk dapat menggerakkan 
motor DC ini maka diperlukan suatu rangkaian tambahan berupa rangkaian penguat daya yang disebut dengan rangkaian penggerak (driver circuit).

Kecepatan motor DC dapat dikendalikan dengan mengubah-ngubah tegangan yang dikenakan pada motor, pada dasarnya motor DC merupakan peralatan listrik yang megubah energi listrik menjadi energi mekanis.

Motor terdiri dari 2(dua) bagian utama yaitu stator dan rotor, Stator atau bagian diam terdiri dari magnet permanen dan rotor atau bagian yang berputar terdiri dari kumparan-kumparan tembaga yang ditanam dicelah-celah inti besi rotor.

Kumparan-kumparan tembaga pada rotor sama prinsipnya seperti konduktor. Dimana setiap konduktor yang mengantar arus mempunyai medan magnet disekelilingnya, Kuat medan tergantung dari kuat arus yang mengalir.

\subsubsection{Dasar-dasar Motor DC}

Pada percobaan Maxwell, bilamana arus listrik yang mengalir dalam kawat arahnya menjauhi kita (maju), maka medan-medan yang terbentuk disekitar kawat searahnya dengan putaran jarum jam. Sebaliknya bila mana arus listrik mengali dalam kawat arahnya mendekati kita (mundur) maka medan-medan magnet yang terbentuk disekitar kawat arahnya berlawanan dengan arah putaran jarum jam.

Besarnya gaya dapat dihitung :

$$
\mathbf{F}=\mathbf{B} \text {. } \mathbf{I} \text {. } \mathbf{L}
$$

Dimana:

$$
\begin{aligned}
& \mathrm{F}=\text { Gaya (Newton) } \\
& \mathrm{B}=\text { Kerapatan Fluk(wb/m2) } \\
& \mathrm{I}=\text { Kuat arus (ampere) } \\
& \mathrm{L}=\text { Panjang kumparan (meter }
\end{aligned}
$$

\section{Hasil Dan Perancangan}

\subsection{Desain Sistem Secara Umum}

Secara umum bentuk dari sistem robot pendeteksi halangan ini terdiri atas sistem mekanik dan rangkaian elektronik. Gerakan dari sistem mekanik akan ditentukan oleh gerakan simulasi yang digunakan, sedangkan rangkaian elektronika berfungsi untuk memberikan data berupa sinyal yang akan diproses oleh mikrokontroler sesuai logika program yang yang dirancang. Untuk menggambarkan sistem yang dibangun ini secara umum dan menyeluruh digunakan Data Flow Diagram yang terdiri dari :

\subsubsection{Context Diagram}

Context diagram adalah pendefenisian terhadap system yang akan dirancang yang bersifat menyeluruh. Context diagram digunakan untuk memudahkan proses penganalisaan terhadap system yang dirancang secara keseluruhan. Dalam hal ini context diagram berfungsi sebagai media yang terdiri dari suatu proses dan beberapa buag eksternal entity. Adapun context diagram yang dimaksud dapat dilihat pada gambar berikut : 


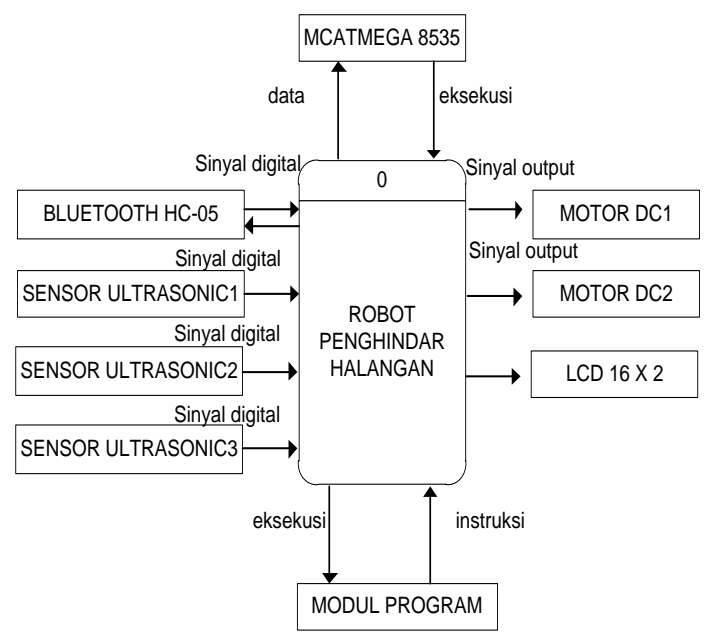

Gambar 3.1 Context Diagram

\subsubsection{Data Flow Diagram (DFD) Level 0}

Untuk memberikan penjelasan lebih mendetail mengenai sistem yang sedang dibangun ini bisa dilihat pada data flow diagram. Dimana didalam DFD jumlah entitynya harus sama dengan jumlah entity context diagram. Pada gambar 3.2 terlihat bahwa eksternal entity pada context diagram sama dengan entity pada DFD level 0, sedangkan proses dinaikkan dari 1 proses menjadi 6 sub proses. Adapun proses tersebut dapat dilihat pada gambar 3.2 dibawah ini.

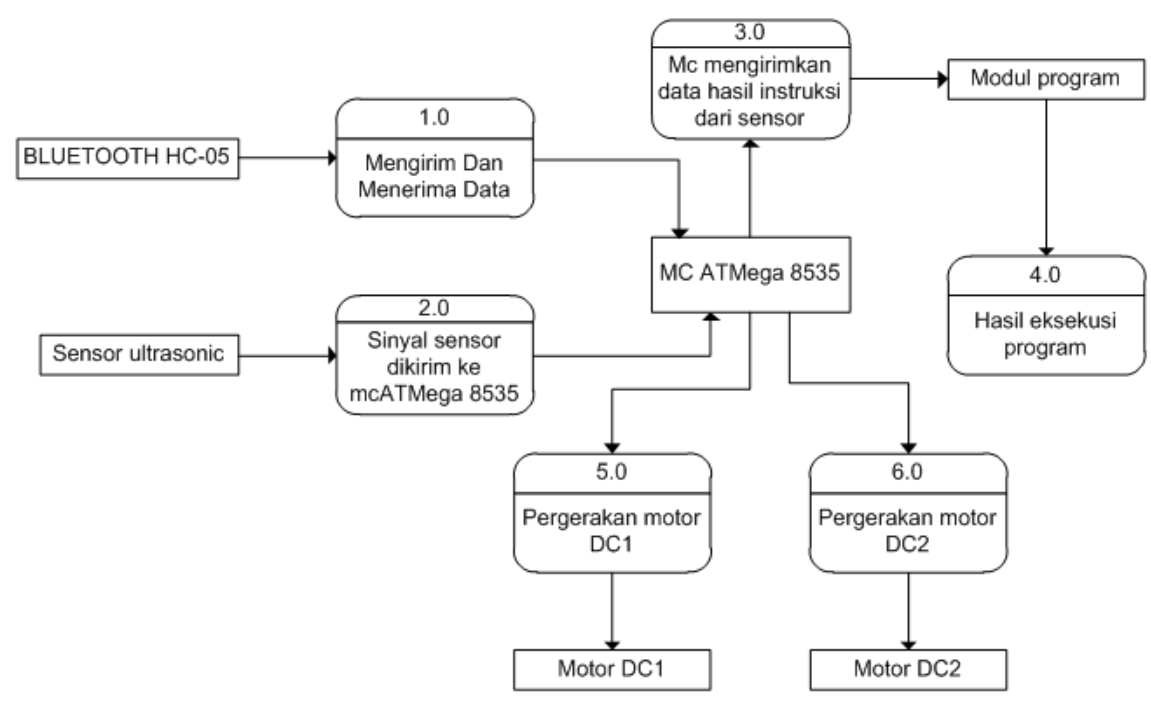

Gambar 3.2 Data Flow Diagram (DFD) Level 0

Setelah Bluetooth terkoneksi dengan robot maka robot akan aktif dan motor DC akan bergerak sesuai dengan perintah yang di kirim oleh Smartphone dan bluetooth akan mengirim dan menerima data ke mikrokontroler (1.0). Sinyal sensor ultrasonik di kirim oleh MCATmega8535 (2.0). Microkontroller akan mengirim data hasil instruksi dari sensor (3.0). Modul program akan menghasilkan hasil eksekusi (4.0). Mikrokontroler akan mengirim sinyal ke driver motor DC, driver motor DC akan melanjutkan sinyal tersebut menghidupkan motor DC untuk mengerakan $\operatorname{robot}(5.0$ dan 6.0). 


\subsubsection{Rancangan Fisik Alat}

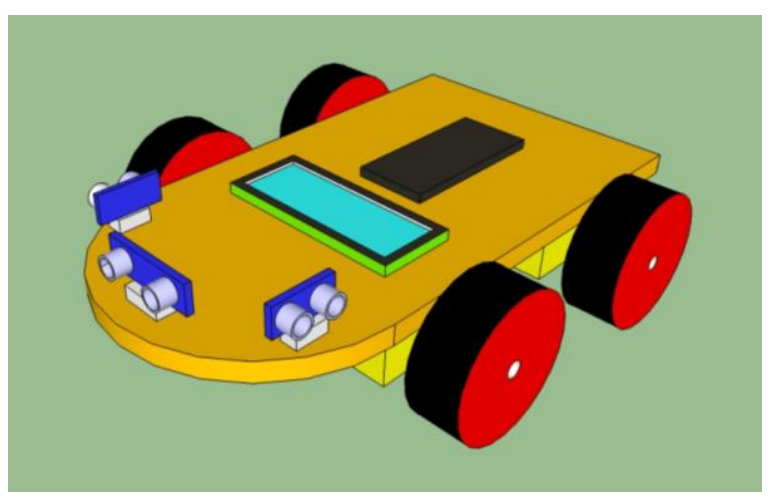

Gambar 3.3 Rancangan Fisik Alat

\subsubsection{Rancangan Modul Program}

Pada sub bab ini akan dijelaskan tentang modul program yang digunakan untuk mengontrol kinerja dari robot yang dirancang. Untuk lebih mudah dimengerti rancangan modul dapat dibagi menjadi dua bagian yaitu: Flowchart dan listing program.

\subsubsection{Flowchart}

Agar modul program yang dirancang memiliki struktur dengan kualitas yang baik dan mudah dimengerti, maka sebelum pembuatan listing program perlu diawali dengan penentuan logika program. Logika dasar gambaran pada penulisan ini adalah dengan menggunakan flow chart seperti gambar berikut:

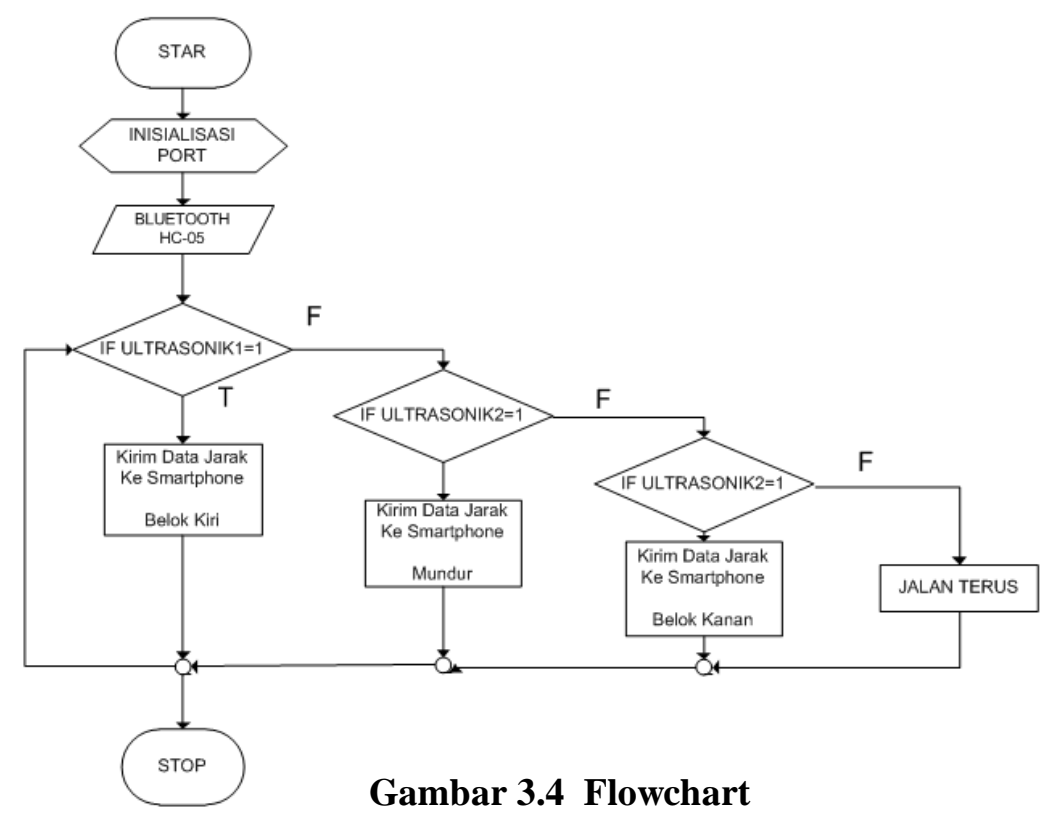


UPI YPTK Jurnal KomTekInfo Vol. 5, No. 1, Juni 2018, Hal.110-121 ISSN :2356-0010 | eISSN :2502-8758

Copyright@2018 by LPPM UPI YPTK Padang

\subsubsection{Pengujian Sistem}

Pertama aktifkan Robot kemudian koneksikan Smartphone ke Bluetooth yang ada pada robot, setelah terkoneksi kemudian jalan kan aplikasi pada smartphone. Tampilan aplikasi pada smartphone. Bisa dilihat seperti gambar berikut:

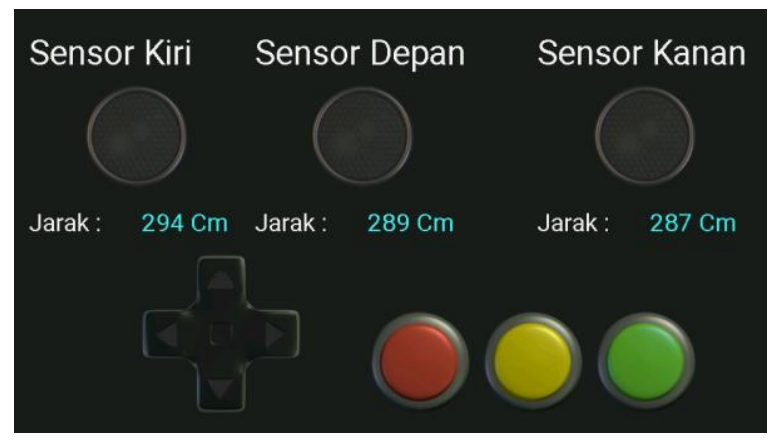

\section{Gambar 3.5 Tampilan Aplikasi Smartphone Kondisi 1}

Tampilan pada gambar 3.5 adalah tampilan ketika robot tidak ada halangan sama sekali, bisa dilihat pada nilai yang dimunculkan pada aplikasi, Sensor kiri Jarak : 294 Cm, Sensor Depan Jarak : 289 Cm dan Sensor kanan Jarak : $287 \mathrm{Cm}$.

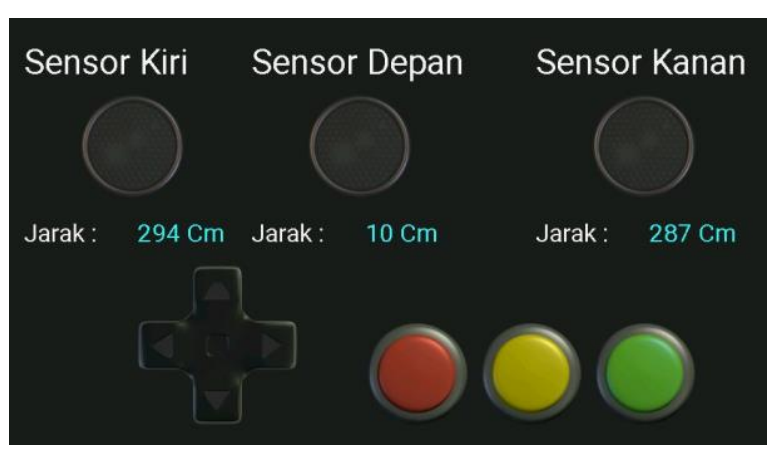

\section{Gambar 3.6 Tampilan Aplikasi Smartphone Kondisi 2}

Tampilan pada gambar 3.6 adalah tampilan ketika robot ada halangan di depan, bisa dilihat pada nilai yang dimunculkan pada aplikasi, Sensor kiri Jarak : 294 Cm, Sensor Depan Jarak : 10 Cm dan Sensor kanan Jarak : 287 Cm.

Tombol yang ada pada Aplikasi berfungsi sebagai penggerak robot untuk melakukan manufer, dan sensor tetap akan aktif mendeteksi halangan yang ada pada sekitaran wilayah Robot.

\subsubsection{Tampilan Fisik Alat}




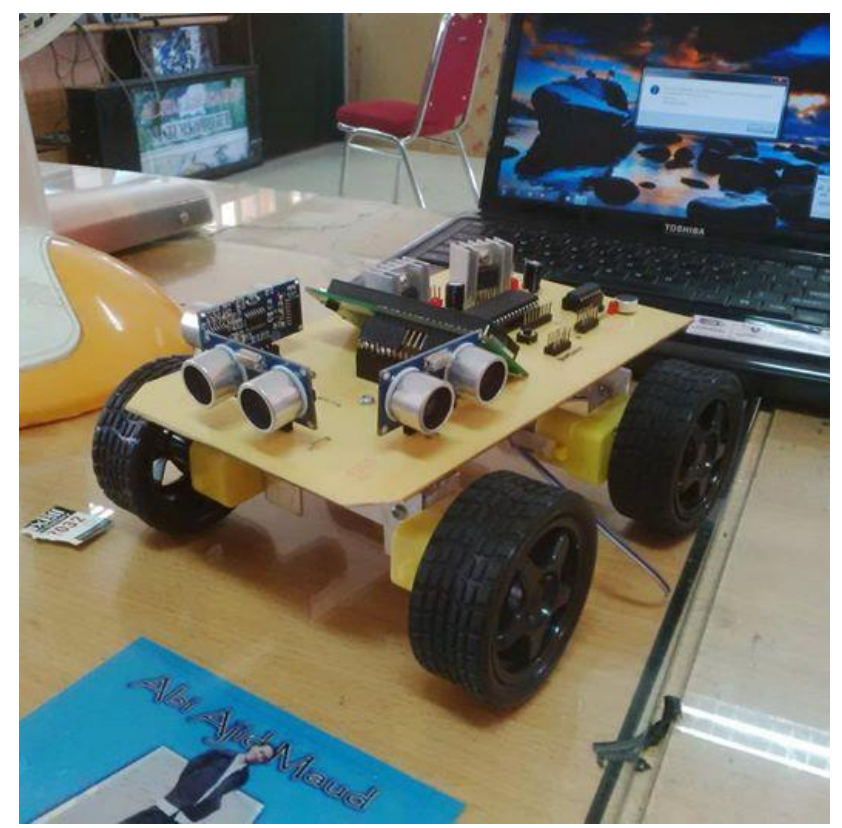

Gambar 3.5 Tampilan Fisik Robot

\section{KESIMPULAN}

Berdasarkan hasil pengujian yang telah dilakukan, dapat diambil kesimpulan-kesimpulan, yaitu:

a. Dengan menggunakan bluetooth HC-05 dapat memudahkan koneksi Robot dengan Smartphone sehingga Robot bisa melakukan perintah pergerakan dan mengirimkan data jarak halangan yang ada pada ruang lingkup robot, sehingga kita bisa memonitoring jarak halangan.

b. Untuk pengiriman data dari Robot ke Smartphone dengan menggunakan Bluetooth HC-05 cukup cepat sehingga data yang didapat cukup akurat dengan kondisi robot.

\section{DAFTAR REFERENSI}

[1] Amirin, Tatang M. 1996. Pokok - Pokok Teori Sistem . PT. RajaGrafindo Persada: Jakarta.

[2] Andrianto, Heri. 2008. Pemograman Mikrokontroler AVR ATMEGA16. Bandung: Penerbit Informatika

[3] Depari, Ganti. 1992. Belajar Teori dan Ketrampilan Elektronika. Bandung:PT. Elex Media Computindo

[4] Hermanto, Dedy (2015), "Pengontrolan Gerak Mobile Robot Menggunakan Sensor

[5] Jogiyanto, HM. 1992. Intisari Elektronika. Jakarta : PT. Elex Media Computindo

[6] Kusumadewi, Sri (2003), “Artificial Intelligence (Teknik dan aplikasinya)".Yogyakarta: Graha Ilmu.

[7] Malik, dkk. 1997. Bereksperimen dengan Mikrokontroler 8051. Jakarta : PT. Gramedia.

[8] R.Annamaria, Várkonyi-Kóczy (2010)," A Complexity Reduced Hybrid Autonomous Navigation Method for In-Door Robots

[9] Pitowarno, Endra (2006), "Robotika: Desain, Kontrol, dan Kecerdasan Buatan". Yogyakarta: Andi.

[10] Suksmadana, Budi (2011), "Rancang Bangun Robot Mobil Menggunakan Logika Fuzzy Untuk Bernavigasi Berbasiskan Mikrokontroller AVR ATMega8535"

[11] Sutojo, T, Mulyanto, Edi, Suhartono, Vincent, Dr. (2011),"Kecerdasan Buatan".

[12] Triwiyatno, Aris (2011), "Buku Ajar Sistem Kontrol Analog.", Hlm. 1-11. <URL:http://aristriwiyatno.blog.undip.ac.id/files/2011/10/Bab- $\quad 1 \quad$ Konsep-Umum-SistemKontrol.pdf>. diakses pada 22 Mei 2016. 
UPI YPTK Jurnal KomTekInfo Vol. 5, No. 1, Juni 2018, Hal.110-121 ISSN :2356-0010| eISSN :2502-8758 Copyright@2018 by LPPM UPI YPTK Padang 